\title{
Ariel al trasluz de Cuba y Martí
}

\section{Ariel against the light of Cuba and Martí}

\section{Osmar Sánchez Aguilera*}

Resumen: En este artículo se pretende demostrar que el ensayo más famoso de Rodó tiene entre sus raíces más notables las cubanas, así en la dimensión políica como en la cultural, y en su contenido tanto como en su circulación editorial. La correspondencia del escritor uruguayo con varios pares suyos de Cuba ofrece una mina de evidencias al respecto. Lugar especial entre esas raíces ocupa José Martí y particularmente quizá su ensayo "Nuestra América".

Palabras clave: Ariel, Cuba, Intelectuales, José Martit, "Nuestra America”.

ABSTRaC: This paper is intended to demonstrate that the most famous essay written by José Enrique Rodó has among its most noticeable roots the Cuban ones. This both in its political and cultural sides, as well as in its contents and circulation. The corpus of letters exchanged between the Uruguayan writer and his Cuban peers offers plenty of proofs about this. Special place among these is the influence of José Martí, mainly, maybe, his essay "Our America".

Key Words: Ariel, Cuba, Intellectuals, José Martí, "Our America"

Recibido: 22 de enero de 2018

Aceptado: 5 de marzo de 2018

Tecnológico de Monterrey. Escuela de Humanidades y Educación, campus Ciudad de México (osaguilera@yahoo.com). 


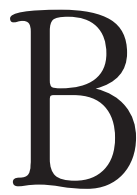

eneficio principal de las efemérides, si es que no único en los casos de escritores y escritoras, la lectura y acaso más la relectura a que esas fechas cerradas inducen, esta vez ha tenido bastante material entre el cual escoger o repartirse: ceñidos a la literatura hispanoamericana, el año 2017 fue pródigo en inducciones y estimulaciones de lecturas y relecturas, por las varias efemérides que en él convergieron. ${ }^{1}$ Autor de cuando menos un ensayo no sólo canónico sino además clásico en la tradición de ese género comprendida por la lengua española, José Enrique Rodó debía ser uno de los escritores beneficiados ese año por ser el del centenario de su muerte. Inevitable entonces era volver a visitarlo.

Resultados sobresalientes de esta nueva visita a su Ariel han sido, en mi caso, primero, confirmar el vigor que conservan las más de sus fundamentaciones sobre por qué no sería procedente que la América Latina tomara como su modelo civilizatorio a la otra América; y segundo, reparar en el carácter seminal de su ensayo, no sólo para la tradición de la que él mismo es un referente, sino también para la tradición poética hispanoamericana.

El resultado primero me ha llevado a pensar en otro ensayo bastante reciente que termina por atraerlo a su órbita, o por insertarse en la suya: La sociedad del espectáculo, de Mario Vargas Llosa (2012): cómo no percibir nexos incluso causales entre el estado de cosas lamentado por este escritor a inicios del siglo XXI y el modelo de cultura con respecto al cual Próspero intentaba prevenir a sus discípulos en el umbral del siglo xx. Aquél vendría a ser, en gran medida, consecuencia de la expansión o el desborde transnacional - la globalización - del que el viejo maestro advertía: "renunciemos a ver el tipo de una civilización ejemplar, donde sólo existe un boceto tosco y enorme, que aún pasará por muchas rectificaciones sucesivas, antes de adquirir la serena y firme actitud con que los pueblos que han alcanzado un perfecto desenvolvimiento de su genio

1 Por ejemplo, centenarios de Juan Rulfo, de Gonzalo Rojas, de Augusto Roa Bastos, de Violeta Parra, además de fechas redondas de primeras ediciones de libros como Cien años de soledad, La expresión americana, Visión de Anábuac, entre otros. 
presiden al glorioso coronamiento de su obra" (Rodó 2014: 150). Profecía confirmada más de un siglo después podría considerarse la observación de que "Hoy, ellos aspiran manifiestamente al primado de la cultura universal, a la dirección de las ideas, y se consideran a sí mismos los forjadores de un tipo de civilización que prevalecerá" (146). ${ }^{2}$

No insinúo que Rodó y su Ariel hayan estado en el radio de las referencias conscientes de Vargas Llosa (Guy Debord, Lipovetsky, Frédéric Martel, T. S. Eliot, George Steiner, entre otros) al momento de reunir y entretejer sus reflexiones sobre la situación de la cultura (o lo que para él sería su sucedáneo) durante la modernidad tardía, pero bastaría reparar en algunas de las nociones más reiteradas en su ensayo a la hora de caracterizar la cultura correspondiente (v. gr., masificación, democratización, frivolidad, entretenimiento, banalización, mercado, desaparición del intelectual comprometido) para percibir su consanguineidad con otras equivalentes en el ensayo de Rodó. Incluso la nostalgia de Vargas Llosa por ciertas distinciones perdidas o muy relativizadas en la sociedad del espectáculo, como el respeto a la jerarquía, el elitismo y el intelectual, abonaría también el parentesco insinuado con el célebre ensayo fundacional de José Enrique Rodó.

Para ilustrar el resultado segundo de esta nueva visita al Ariel, el referido a su carácter seminal con respecto a la poesía, bastaría evocar precisamente el denso tramado intertextual que varios poemas de Cantos de vida y esperanza (1905) de Rubén Darío descubren retroactivamente

2 A propósito de la globalización, considero muy pertinente traer a colación la caracterización que hace de ella Pierre Bourdieu: "Esta palabra, que funciona como un santo y seña y una consigna es, en efecto, la máscara justificadora de una política que procura universalizar los intereses particulares y la tradición particular de las potencias económica y políticamente dominantes, especialmente de los Estados Unidos, y extender al conjunto del mundo el modelo económico y cultural más favorable a esas potencias, presentándolo a la vez como una norma, un deber-ser, y como una fatalidad, un destino universal, de manera que le haga obtener una adhesión o, al menos, una resignación universales. Es decir, una política que procura, en materia de cultura, universalizar, imponiéndola al universo, las particularidades de una tradición cultural en la que la lógica comercial ha experimentado su pleno desarrollo" (2002: 369-370). 
con ese ensayo que en nada rehúye su atracción por la poesía: v. gr., el célebre verso "Juventud, divino tesoro", prefigurado por líneas del ensayo como "La Juventud que vivís es [...] un tesoro", o "De la Naturaleza es la dádiva del precioso tesoro". Otras líneas, como "ante la faz misteriosa y grave de las cosas", dejan entrever la ascendencia de ese ensayo sobre la poesía más característica de Enrique González Martínez. Y aunque tal vez no es estrictamente un poema, como tampoco un ensayo al uso, Visión de Anábuac (1917) parecería estar in nuce en el pasaje de Ariel que culmina con el símil "como las visiones de Cipango y El Dorado en las crónicas heroicas de los conquistadores" (Rodó 2014: 91). ${ }^{3}$

Tenido por culminación de la prosa modernista, o del ensayo del siglo XIX, Ariel es también semilla de mucha literatura posterior dentro y fuera de su tradición genérica. Como corresponde a un texto clásico que no se ciñe enteramente a las convenciones de un solo género.

Un ejemplo más será suficiente para ilustrar el denso tramado intertextual de ese ensayo con la obra de Darío, y, de paso, nos permitirá adentrarnos en el tema anunciado en el título de esta nota. Pienso ahora en el pasaje en que Próspero señala "el cosmopolitismo [...] como una irresistible necesidad de nuestra formación" (Rodó 2014: 133), el cual va acorde con otra observación de Rodó publicada un año antes en su ensayo "Rubén Darío": en América "sólo puede vivirse intelectualmente de prestado" (201), la que a su vez remite a "Palabras liminares" de 1896, y ésta a otra de junio de 1895 en la que Darío aduce la pobreza intelectual de la región como argumento clave de su rechazo a la consagración de José Martí al activismo político:

Quien escribe estas líneas que salen atropelladas de corazón y cerebro no es de los que creen en las riquezas existentes de América... Somos muy pobres... Tan pobres, que nuestros espíritus, si no viniese el alimento extranjero, se morirían de hambre. iDebemos llorar mucho por esto al que

3 Y más allá de la poesía, resonancia más consciente de esa deuda de Alfonso Reyes con Rodó asoma en un pasaje del Ariel que parece haber servido de modelo para un título de madurez plena del polígrafo mexicano: "en la última Thule de su alma" (Rodó 2014: 105). 
ha caído! Quien murió allá en Cuba era de lo mejor, de lo poco que tenemos nosotros los pobres [...] (Darío 1989: 106).

Muy otra es la resonancia que adquiere esa pobreza sobre el trasfondo de aquellos versos de José Martí en los que declara su decisión de apostar todo su capital simbólico y aun su vida misma con y por los pobres: "Con los pobres de la tierra / Quiero yo mi suerte echar", versos en consonancia con una línea ensayística suya del mismo año que Versos sencillos: "Con los pobres había que hacer causa común". Donde Martí había privilegiado, a propósito de la suerte de un sujeto colectivo, la dimensión socioeconómica, Darío destaca, a propósito de Martí, la dimensión cultural-artística, como si también ahí, con esa especie de sobreescritura intentara reacomodar las prioridades del proyecto creador de su colega. ${ }^{4}$

Es precisamente de la huella de Cuba y de Martí en Ariel y en Rodó que quisiera tratar en las páginas que siguen. Bastante consensual entre los estudiosos que se han interesado en explorar los nexos de Rodó, y específicamente de su Ariel, con Cuba y con José Martí, ha sido considerarlos como factores de mucho relieve. En la génesis e historia inicial de efectos de ese ensayo, el papel desempeñado por Cuba en general y representantes de su literatura en particular es uno de los más sobresalientes, si es que no el más sobresaliente, fuera de Uruguay. Esta distinción entre Cuba en la dimensión política y en la cultural y literaria es remontable al propio Rodó, cuando en una carta de 1896 al crítico cubano Rafael María Merchán en que lo invita a colaborar en la Revista Nacional de Literatura y Ciencias Sociales le comenta que:

4 Esta idea de la sobreescritura se refuerza cuando se conoce un artículo del propio Darío publicado tres meses antes en el mismo periódico porteño (La Nación) titulado "La insurrección en Cuba", porque ahí aparece una variante de la fórmula introductoria del pasaje recién citado: "quien estas líneas escribe", sólo que mientras que en ese artículo él se refiere a la dispersión y errancia de los cubanos sobrevivientes de la primera guerra de independencia que Darío ha podido conocer en sus andanzas por diversos países, en aquel otro artículo (de junio de 1895) la fórmula va a concentrarse en la repercusión de la pérdida de José Martí más allá de las circunstancias políticas de Cuba. 
Ud. traerá a sus páginas la representación de la intelectualidad de un pueblo del Continente, cuya autonomía aún no alcanzada en la realidad política, lo está hace tiempo, por manifestaciones verdaderamente honrosas de cultura, en la vida del pensamiento y en el concierto de las letras americanas (Castro 2013: 191-192).

Una es la autonomía, aún no alcanzada, en la dimensión política; y otra, la autonomía, ya confirmada, en la dimensión cultural y literaria del mismo país. De ahí entonces mi aprovechamiento de esa distinción en esta revisión de la huella de Cuba y de varios representantes de su intelectualidad sobre Ariel y la información de Rodó en torno a una y otros.

Respecto de la influencia de Cuba en la génesis de Ariel, Belén Castro ha hecho notar de manera reiterada que su emancipación/ocupación fue motivo de honda preocupación para Rodó y que en ese sentimiento empezó a gestarse Ariel: "La intervención de los Estados Unidos en la guerra hispano-cubana, en 1898, supuso un cataclismo sobre el que Rodó quiso reflexionar a fondo en un ensayo, que llevará por título Ariel" (Castro 2016: 51); "Cuando se produjo la intervención de los Estados Unidos, la noticia encendió en Rodó una fuerte indignación [... ] La emancipación de Cuba, en esas condiciones, no era motivo de alegría, sino de honda preocupación, y en ese sentimiento empezó a gestarse Ariel" (Castro 2016: 56). ${ }^{5}$ ¿No aludiría a ese mismo trasfondo geopolítico regional Gonzalo Zaldumbide, ya en 1919, cuando afirmaba que "Irradiaba [el Ariel] una helénica gracia de persuasión y de serenidad [pero] era, sin embargo, el fruto de una angustia"? (86). Por su parte, Emir Rodríguez Monegal señalará, casi medio siglo después que Zaldumbide, sobre el impacto de ese mismo aconteci- miento histórico, que

Mientras Rodó tomaba posesión de su cargo de catedrático de Literatura, ocurría en otro extremo de América el desenlace de la guerra de España

5 La propia Belén Castro, en otro estudio, llega a conjeturar que el hecho de "que el padre de Rodó hubiera vivido en Cuba antes de establecerse en Montevideo [...] pudo añadir otras razones afectivas a la simpatía del escritor por la causa cubana" (2013: 185 nota 11). 
con los Estados Unidos por la posesión de Cuba. Rodó acusó de inmediato el efecto de este acontecimiento. Su conciencia de americano, su amor por la madre patria, hasta su conciencia latina, sintieron como algo propio el Desastre (Rodríguez Monegal 1967: 30).

"Tal convicción [según él] precipitó la realización de Ariel" (30). Prueba del inmediato interés suscitado por ese suceso histórico de implicaciones tan definitorias no sólo para la América Latina ofrece una carta del 19 de mayo de 1898 en la que Rodó exhorta a un político y escritor compatriota suyo a que le envíe "el opúsculo que acaba de publicar sobre la cuestión hispanocubana. Muchos son mis deseos de leerlo, por lo que le ruego no demore el envío [... ]" (Rodó 1967: 1369). Ya leído el opúsculo, casi dos semanas después volverá a dar prueba de su mucho interés por lo que él llama "la trascendental cuestión hispanoamericana" al dirigirse nuevamente al autor del mismo, ahora para solicitarle otro ejemplar ("si le sobra algún ejemplar de su folleto") que él remitiría "a un ilustre crítico colombiano que me pide obras de nuestro país" (1967: 1370).

Respecto de la mediación y aun huella de representantes de la literatura cubana sobre Rodó y su Ariel, los testimonios no son menos abundantes. Ya en mayo de 1900, o sea a escasos dos meses de la primera edición de Ariel, Rodó dirige una carta al muy reconocido intelectual José Enrique Varona - "el primer intelectual de Cuba" al decir de Pedro Henríquez Ureña (2000: 98) - para acompañar el envío de un ejemplar de ese ensayo en la que le explica:

La respetuosa admiración que su alta personalidad intelectual me ha impuesto siempre, y a la que concurren no sólo los indiscutidos merecimientos de usted, sino también mis entusiasmos de americano por cuanto glorifica y enaltece a nuestra América, me mueve hoy a enviarle un ejemplar de mi último libro, que sea como el homenaje en que se haga sensible esa admiración muy sincera (1967: 1330).

Y en muestra no sólo adicional sino excepcional de esa gran admiración entre todos sus corresponsales, hacia el final de la carta llega a identificar a su destinatario con el sujeto enunciador del "sermón laico" 
-y principal enunciador - que centraliza el ensayo: "Usted puede ser en realidad el Próspero de mi libro. Los discípulos nos agrupamos alrededor de usted para escucharle como los discípulos de Próspero" (1331). Así fuera no más por la presencia de ese ejemplar del Ariel en La Habana y en manos de un maestro universitario tan influyente como Varona, resulta difícil aceptar que "en 1904 nadie lo había leído en Cuba", como lo concluye Real de Azúa con base en una carta de Max Henríquez Ureña (1985: xxxiii, nota 19). Que "nadie" hubiera emitido un juicio público sobre ese ensayo no es prueba suficiente de que "nadie" lo hubiera leído en esos tres o cuatro años en Cuba. ${ }^{6}$

Empero, como bien lo observa Gustavo San Román, "la apreciación de Rodó en Cuba comienza con dos grandes intelectuales vecinos, los hermanos dominicanos Pedro (1884-1946) y Max (1885-1968) Henríquez Ureña, el primero sobre todo con su firma de estudioso y el segundo durante una larga residencia y rica actividad cultural en la isla". Ciertamente, de mucha consideración también en la ascendencia de Cuba en la suerte del más famoso ensayo de Rodó es el hecho, tal vez azaroso, de que Max y su hermano Pedro se hubieran establecido en la isla a inicios del siglo xx y con ello contribuyeran a fomentar y expandir la entonces incipiente historia de efectos del ensayo cuya tercera edición y primera fuera de Uruguay había tenido lugar en República Dominicana. Cuando menos, Pedro ya había leído el Ariel antes de salir de República Dominicana, bajo el estímulo de una discípula de Salomé Ureña, a quien él atribuye el mérito de su formación en la literatura moderna, Leonor Feltz, "la mujer más ilustrada de Santo Domingo" y "la discípula favorita de mi madre" (2000: 61). La huella dejada en él por esa temprana lectura se le hará evidente en Nueva York a inicios de 1901: "Mis impresiones se atropellaban un poco,

6 La cita textual de Max Henríquez Ureña en esa carta de agosto de 1904 a Rodó es: "A Ud. se le conoce de nombre, pero casi nadie lo ha leído en Cuba" (énfasis mío). Sirva ella, de paso, para confirmar que la correspondencia entre Max y Rodó estaba en marcha antes de la carta de Rodó en que se refiere tan elogiosamente a Martí. He tomado la cita del artículo de Raffaele Cesana: "El diálogo entre la misiva y el ensayo: la correspondencia entre los hermanos Henríquez Ureña y José Enrique Rodó" (2017: 222). 
y yo las veía todas a través del prejuicio anti-yankee, que el Ariel de Rodó había reforzado en mí, gracias a su prestigio literario; no fue sino mucho después, al cabo de un año, cuando comencé a penetrar en la verdadera vida americana, y a estimarla en su valer" (2000: 66). Desde luego, más allá de cualquier visión sesgada o incompleta de la cultura estadounidense por parte de Rodó, no habría que perder de vista que lo que a él le interesaba hacia 1898-1899 no era tanto ofrecer un panorama de la misma como contrarrestar la obra de la "nordomanía", para lo cual debía acentuar las limitaciones de esa otra cultura para ejercer como modelo civilizatorio de América Latina.

La edición por entregas de Ariel que Max publicó en la revista Cuba Literaria fue introducida por un artículo de su hermano. ${ }^{7}$ Ya para entonces se había iniciado la correspondencia de Max con Rodó, pues en una carta de finales de 1904 enviada a Santiago de Cuba, el uruguayo acusaba recibo de "su carta sobre Ariel" (1967: 1442) en la que el intelectual dominicano le había solicitado su autorización para emprender la edición mencionada.

Dos datos más de esa carta ameritan mención por su relevancia en este recuento de la mediación de Cuba y de algunos intelectuales cubanos en la génesis e inicial historia de efectos del Ariel: uno es el fuerte ánimo americanista que, si por una parte marca el entramado ideotemático de ese ensayo, por la otra preside la labor difusora y propagandística de que lo hace objeto Rodó. "Trabaje usted [recomienda a su joven destinatario], persevere, piense en el porvenir; quiera mucho a su América, a nuestra América, que es nuestra grande y única patria" (1967: 1442). El otro dato de mucho relieve en esa carta concierne al conocimiento y la admiración de que da muestras Rodó sobre José Martí: "Y si él [Ariel] no llevara ya su dedica-

Según Alfonso García Morales "Ariel salió como suplemento de la revista entre enero y abril de 1905, alcanzando así su cuarta edición. Pedro se encargó de presentarlo en un artículo en el que aceptaba el mensaje idealista de Rodó, pero ponía reparos a lo que le parece una visión simplista de los fallos y peligros de la civilización norteamericana" (1993: 97). De acuerdo con este investigador, esa sería la segunda edición de Ariel realizada fuera de Uruguay. 
toria - nacida, por decirlo así, de sus mismas entrañas-, propondría a usted que a la memoria de Martí dedicáramos la edición cubana de Ariel" (1967: 1442). Así de honda es para esas fechas la admiración del intelectual uruguayo hacia su colega cubano, muerto en combate por la independencia de su país natal casi una década antes. Si no fuera porque el ensayo está dedicado - con mucha pertinencia, además - "A la juventud de América", Rodó hubiera deseado que la edición preparada por Max y Pedro Henríquez Ureña en Santiago de Cuba se dedicara "a la memoria de Marti". Líneas antes, en esa misma carta, Rodó le había solicitado a Max: "Escribe usted en la patria de Martí. Ponga usted su empresa bajo los auspicios de esa gran sombra tutelar" (1967: 1442). La nota americanista va de la mano con la memoria de Martí en Rodó, y viceversa.

No será esa la única vez que Rodó manifieste semejante respeto y admiración por su muy reconocido predecesor cubano. En una carta fechada en enero de 1914 le comentará a su amigo personal Hugo D. Barbagelata, con motivo de El mirador de Próspero: "Allí, entre otras cosas que le son conocidas, encontrará usted cosas nuevas, como el estudio de [Juan] Montalvo, en el que he puesto tanto esmero y amor como en pocos escritos míos. Quisiera escribir otros estudios de ese género sobre personalidades americanas. Por ejemplo, el gran Martí" (1967: 1459). Como su destinatario es ahora un compatriota suyo de toda su confianza, no procedería ni remotamente pensar en la cortesía para explicar esa referencia tan elogiosa al eminente escritor y activista político cubano. No escribe Rodó, sencillamente, 'Martí', o 'José Martí', sino "el gran Martî".

Ese mismo año volverá Rodó a expresar su interés por ese estudio sobre Martí en una carta en la que el cubano Carlos de Velasco alude a esa especie de tarea pendiente, cuando le solicita alguna colaboración para la revista Cuba Contemporánea: "El estudio sobre Martí a que usted se refiere es una idea que aún no he realizado, si bien me agrada e interesa el tema muchísimo. En caso de que lo escribiera en breve, puede usted estar seguro de que enviaría a Cuba Contemporánea las primicias de él" (1967: 1475).

Casi diez años antes, en un discurso pronunciado con motivo del traslado a Montevideo de los restos de un compatriota muerto en el des- 
tierro, Rodó, al momento de argumentar sobre la idea de América Latina como una sola patria transnacional, vuelve a dar fe de su alto aprecio por José Martí, así como de su asociación de la memoria de éste con el americanismo:

Alta es la idea de la patria; pero en los pueblos de la América Latina, en esta viva armonía de naciones vinculadas por todos los lazos de la tradición, de la raza, de las instituciones, del idioma, como nunca las presentó juntas y abarcando tan vasto espacio la historia del mundo, bien podemos decir que hay algo aún más alto que la idea de la patria, y es la idea de la América: la idea de la América, concebida como una grande e imperecedera unidad, como una excelsa y máxima patria, con sus héroes, sus educadores, sus tribunos; desde el golfo de México hasta los hielos sempiternos del Sur. // Ni Sarmiento, ni Bilbao, ni Martí, ni Bello, ni Montalvo, son los escritores de una u otra parte de América, sino los ciudadanos de la intelectualidad americana (1967: 513).

En conocimiento de la inclusión de Martí en ese listado canónico de intelectuales (mayormente ensayistas) hispanoamericanos, no ha de sorprender la impugnación que dos años después hace Rodó de una antología literaria de la región que excluye, entre otros escritores modélicos, precisamente al cubano. En su extensa reseña de la misma, el escritor uruguayo refuta con una argumentación bastante demoledora el fundamento que le resulta menos coherente para esas y otras exclusiones de escritores considerados canónicos por él mismo:

Afirma el señor Ugarte en su advertencia, y lo confirma y amplía en su resumen histórico, que "la verdadera actividad literaria americana empieza con las generaciones jóvenes". Cualquiera que sea el sentido que a esta afirmación deba atribuirse, no es posible asentir a ella.

Si vale tanto como establecer la superioridad de mérito intrínseco, en pensamiento o en parte, de la obra de las nuevas generaciones sobre la de aquellas que las precedieron, me parece un rasgo un poco temerario de optimismo o de amor por las cosas que se tienen cerca. Difícil sería demostrar que, después de Sarmiento, la juventud americana haya dado de sí el super-Sarmiento. No es punto muy seguro que, después de Montalvo y de Martí, tenga la juventud resplandores con que ofuscar los nombres de Montalvo y Martí (1967: 634). 
Pareciera que lo que ha indispuesto a Rodó en relación con esa antología publicada en París en 1905 es su pretensión inaugural o adánica, con la invalidación consiguiente de escritores de la época previa que el escritor uruguayo tiene por muy valiosos y que además no habrían sido superados o invalidados por escritores o poéticas posteriores, entre los cuales menciona a José Martí como ejemplo de la precariedad del fundamento histórico-literario de esa antología. Pero, en su refutación Rodó llega a más, pues no sólo repara en omisiones como esa a escala individual, sino que lleva la afirmación clave de que "la verdadera actividad literaria americana empieza con las generaciones jóvenes" a una dimensión más amplia, colectiva, y ahí razona que si el sentido de tal afirmación es válido para las generaciones anteriores, no lo es menos para las generaciones nuevas, por cuanto "la literatura hispanoamericana como obra social, como organismo autóctono y maduro, ni ha existido antes de ahora ni existe todavía" (1967: 634). Así que el planteamiento polémico de la antología comentada resultaría refutado tanto a escala de la selección de escritores individuales como de su identificación con el punto inicial de toda una literatura supranacional.

Con razón resume Rodríguez Monegal sobre esa reseña que

su comentario vale por una consideración original del problema. No se limita a refutar a Ugarte en su audaz afirmación de la supremacía de la joven literatura hispanoamericana. [...] Rodó, cuyo conocimiento de las letras americanas era más completo y sólido que el de Ugarte, demuestra su actitud sobria de valoración, su descreimiento en las maravillas de la nueva promoción. Y en este sentido, sus palabras, difundidas desde una tribuna literaria importantísima y dichas con autoridad, significaron una valoración cabal del estado de la literatura hispanoamericana (1967: 94).

Tal vez alguna memoria de Martí perviviera todavía entre el público lector del diario en el que fue publicada esa reseña: La Nación, de Buenos Aires, por haber sido el escritor cubano un colaborador constante desde Nueva York, donde fungió durante casi una década como corresponsal de ese periódico tan memorable para la historia literaria hispanoamericana. 
De enorme interés en este recuento de las relaciones de Rodó y su Ariel con Cuba y algunos de sus intelectuales es la correspondencia epistolar que él sostuvo en los años finales de la década de 1890 con Rafael María Merchán, escritor cubano que se desempeñaba por entonces en Colombia como representante del Partido Revolucionario Cubano, el órgano de dirección ideológica de la causa independentista que había sido fundado por José Martí en 1892 y dirigido por él hasta su muerte. Esas cartas correspondientes a los años 1896, 1897 y 1899 no dejan duda alguna sobre el temprano conocimiento de la situación política cubana por parte de Rodó, ni tampoco de la simpatía de éste hacia la causa independentista implicada en esa situación. Así, por ejemplo, en una carta de diciembre de 1896, ante la imposibilidad de Merchán de colaborar en la Revista Nacional de Literatura y Ciencias Sociales, le responde, comprensivo:

Lamento que la situación presente de su espíritu nos prive por ahora de la honra de su colaboración, pero comprendo lo poderoso del motivo que asílo quiere, y le acompaño con todas mis simpatías y todos mis votos en las patrióticas agitaciones de su alma. [¿] Y qué otro sentimiento pueden inspirar a los ciudadanos de la América libre los esfuerzos del pedazo de América que aún lucha por su libertad sino el de la adhesión y el entusiasmo más sincero? (apud Castro 2013: 195).

No son simpatía o comprensión los términos que mejor caracterizarían su posición con respecto a la Guerra de independencia cubana, sino "adhesión" y "entusiasmo más sincero". En esa misma carta, a seguidas, sigue fundamentando esa postura, ahora más como vocero de sus compatriotas:

A pesar de nuestras propias inquietudes, que son absorbentes y angustiosas en el momento actual, los orientales no permanecemos indiferentes a la suerte de la heroica patria de U. Para mostrárselo, y en la seguridad de que ha de interesarle cuanto se refiera a las manifestaciones de simpatía que se tributan a la nobilísima causa de ustedes, le envío adjunto un recorte de diario donde se refieren las iniciativas tomadas para protestar adhesión a la independencia de Cuba (apud Castro 2013: 195). 
Conviene retener al menos dos de las expresiones con que se refiere a la causa independentista cubana: "la suerte de la heroica patria de U.", "la nobilísima causa de ustedes". Meses después, ya en 1897, va a reiterar en otra carta esa postura suya y de sus compatriotas hacia la independencia cubana en términos muy similares, al comprobar que la carta previa no había sido enviada por un descuido: "Respecto a los acontecimientos que se desenvuelven en la heroica patria de Ud. [...] los orientales no permaneceríamos indiferentes a la suerte de la independencia cubana"; "la noble causa de la libertad de Cuba" (apud Castro 2013: 197). Conocido el interés con que Rodó siguió el desenvolvimiento de la guerra cubana contra la ocupación española, se entiende mejor su decepción y aun molestia ante el desenlace de la misma, el cual dio al traste a la misma vez con las simpatías de él hacia la causa independentista y también con su proyecto de fomentar una especie de confraternidad moral y literaria hispanoamericana inspirada en su admirado Simón Bolívar. A su trasluz es comprensible que en Ariel prefiriera centrar sus reflexiones en las implicaciones del desenlace de ese enfrentamiento entre dos modelos civilizatorios, presentadas desde el punto de vista del desfavorecido, en vez de particularizar sobre una situación que era, sería o había sido, en algún momento de sus respectivas historias nacionales, bastante compartida por los distintos países de Hispanoamérica.

Su preocupación por el desenlace de la guerra entre España y Estados Unidos en Cuba, y el abundante intercambio epistolar con intelectuales (escritores, periodistas) cubanos como Enrique José Varona, Ramón A. Catalá, Carlos de Velasco, Rafael María Merchán, Dulce María Borrero de Luján, Francisco García Cisneros ${ }^{8}$ o Max Henríquez Ureña (cubano adoptivo) y su hermano Pedro avalan ampliamente la hipótesis de la influencia,

8 Esta figura ha de haber interesado mucho a Pedro Henríquez Ureña durante su estancia en Nueva York a inicios del siglo xx, a juzgar por sus varias menciones en las Memorias del dominicano. Desde luego, el hecho de que además de escritor y caribeño, García Cisneros, fuera esposo de una cantante norteamericana famosa en su momento con quien recorrió no pocas ciudades europeas, ha de haber influido también en ese atractivo, por coincidir con una época de intensa melomanía en la formación intelectual de Henríquez Ureña. 
huella o ascendencia, y no solamente mediación, de Cuba y varios de sus intelectuales en la génesis e historia inicial de efectos de Ariel, así como en la (in)formación correspondiente de su autor.

Todavía un caso más, bastante curioso, podría abonar esa conclusión: el de Federico García Godoy (1857-1924), un temprano y constante seguidor del arielismo y corresponsal epistolar de Rodó, a quien varias fuentes dan por dominicano, pero quien había nacido en Santiago de Cuba y por la decisión de sus padres de emigrar a República Dominicana al inicio de la Guerra de los 10 años en su país natal terminó haciendo de esa isla vecina su propio hogar. Complementario, en ese sentido, sería su caso al de los hermanos Pedro y Max Henríquez Ureña, dominicanos que emigraron a Cuba a inicios del siglo XX, años después de que García Godoy emigrara a República Dominicana. Novelista, ensayista y crítico literario, García Godoy sobresalió por su americanismo, ${ }^{9}$ por su apropiación afectiva y novelística de la historia de República Dominicana y por su entusiasta apego a los valores distintivos del Ariel. ${ }^{10}$ Testimonio suficiente de esa amistad y de esa comunión con los valores propagados por Ariel es que una de las cartas enviadas por Rodó a él pasara a integrar El mirador de Próspero (1913) bajo el título "Una bandera literaria". En esa carta-ensayo sobresale, una vez más, el programa americanista del célebre escritor uruguayo y su confianza en la contribución orientadora que podían hacer los intelectuales de la región al mismo: "que la obra del escritor concurra, como una fuerza positiva, al gobierno de las ideas y las pasiones" (1967: 643).

Por su valor programático respecto del ideario artístico y crítico-literario de Rodó ese texto amerita más amplio comentario. Véase, por ejemplo, esta lúcida observación sobre los beneficios recíprocos de una posible cooperación entre el arte y la actividad política en las circunstancias de Hispanoamérica:

9 Precisamente Americanismo literario (1918) se titula uno de sus libros, en el cual incluye un estudio sobre José Martí. Ese libro fue publicado en la Biblioteca Andrés Bello, dirigida por el venezolano Rufino Blanco Fombona, otro admirador del escritor y héroe cubano, además de corresponsal distinguido entre los de José Enrique Rodó.

10 Carlos Real de Azúa (1985: XXIv) lo incluye entre los pioneros más fieles del arielismo, aunque lo da, no sin razón desde luego, por dominicano. 
yo he pensado siempre que, aunque la soberana independencia del arte y el valor sustancial de la creación de belleza son dogmas inmutables de la religión artística, nada se opone a que el artista, que, además, es ciudadano, es pensador, es hombre, infunda en su arte el espíritu de vida que fluye de las realidades del pensamiento y de la acción, no para que su arte haga de esclavo de otros fines, ni obre como instrumento de ellos, sino para que viva con ellos en autonómica hermandad, y con voluntaria y señoril contribución se asocie a la obra humana de la verdad y del bien (1967: 643).

El beneficio, según esa manera de considerar el arte y sus relaciones con el entorno político en sentido laxo, sería recíproco. Y hasta un beneficio extra podría venirle al arte como resultado de esa "autonómica hermandad" pues "Aun consideradas estas cosas de un punto de vista puramente estético, nadie podrá negar que el arte se privaría de cierta especie de belleza si renunciara a las inspiraciones y virtualidades que puede recoger en el campo de la agitación civil y de la controversia de ideas [...]" (1967: 643). He ahí el eje de un programa que Rodó no perderá ocasión de difundir entre sus corresponsales privados y su público lector abierto, lo mismo a través de cartas que de artículos, prólogos o ensayos. Particularmente ese programa alcanza mucha vigencia en "las naciones hispanoamericanas del presente tiempo", que son, a fin de cuentas, las que lo han llevado a concebirlo.

Una explicación inserta en esa carta-ensayo de El mirador de Próspero podría ayudar a entender la lógica que ha de haber operado en la decisión de omitir referencias explícitas a la situación particular de Cuba, ya que tanto le había preocupado su suerte, en el contenido de Ariel. Como mismo el caso particular de Cuba en la encrucijada de 1898 le dio pie para reflexionar sobre unas circunstancias socioculturales que eran o podían ser comunes al resto de los países de Hispanoamérica, el caso particular de República Dominicana hacia 1912 le hará notar que sus consideraciones sobre ésta tienen su "legítimo alcance" a nivel continental. Sólo que mientras que en el ensayo destinado "A la juventud de América" el elemento catalizador de sus reflexiones queda afuera o sobreentendido, en la carta privada el elemento catalizador empieza por ser puesto en 
evidencia, máxime si su destinatario es alguien que ha escrito antes sobre ese mismo elemento. Hela aquí:

Por razones de situación geográfica, en la patria de usted adquiere doble oportunidad ese propósito, es más urgente e ineludible la obligación moral de ponerlo en obra; pero el legítimo alcance de él abarca toda la América que habla en la lengua del Descubridor, toda la América nuestra, representada y querida como una magna patria indivisible, en la que es necesario avivar la conciencia de su propia unidad y el entendimiento y el amor de las tradiciones históricas donde esa unidad radica (1967: 643).

Con tantas evidencias a la vista, no sería exagerado afirmar que en los años delta de los siglos XIX y XX Cuba tuvo un papel muy sobresaliente, acaso el más sobresaliente fuera de Uruguay, en el rumbo y la suerte de Ariel. A ese cúmulo de indicios favorecedores de esa conclusión habría que añadir todavía a Jesús Castellanos con su disertación inaugural sobre Proteo en la Sociedad de Conferencias en la Habana, $1910 .{ }^{11}$

Entre sus corresponsales cubanos, únicamente con la poeta Dulce María Borrero de Luján no se refiere Rodó a cuestiones políticas o a Cuba, ni alude tampoco a José Martí, acaso porque no viniera a colación en esa correspondencia (él está acusando recibo de un poemario que contiene un soneto dedicado a él), o acaso porque no los considerara temas propios para tratar con una mujer escritora. Esa carta de enero de 1914 se singulariza también por la visión que deja entrever sobre lo que distinguiría según el ensayista a la producción literaria "verdaderamente" de mujer, pues "la sensibilidad femenina" que él celebra en los versos de esta escritora "no siempre está presente en lo que escriben en verso o en prosa las mujeres

11 Todavía cabría agregar a Eulogio Horta, escritor cubano que publicó dos artículos sobre Ariel, en 1901 y en 1904 (Castro 2013: 189 nota 17); o las dos revistas habaneras tituladas Ariel, de finales de las décadas de 1920 y de 1930, que registra el Diccionario de la literatura cubana (1980). Para extender el recuento de la historia de efectos de Ariel y Rodó en Cuba más allá de esos años delta de los siglos XIX y XX se recomienda el artículo de Gustavo San Román "La recepción de Rodó en Cuba" (2009) y el de Sven Plesch "Ariel y la ilusión del 'hombre nuevo'. Apuntes sobre la temprana recepción de Rodó en Cuba" (2000). 
de talento, a menudo intelectualmente varoniles" (1967: 1471). Es evidente que la delicadeza y el "sentimiento íntimo y suave" son rasgos distintivos para Rodó de esa sensibilidad que habrían escaseado en la poesía (¿o en la literatura en general?) de las mujeres: "¿Cuántas mujeres han versificado en tierra americana con tan positivas y delicadas dotes de poeta? Seguramente pocas, muy pocas [...]" (1967: 1471). "Remanso", el título del soneto dedicado por Dulce María Borrero a Rodó, cabe extenderlo a esa carta entre las intercambiadas por el escritor uruguayo con sus pares cubanos, a partir de las omisiones políticas o martianas en ella.

Es un hecho incuestionable, sin embargo, que José Martí ocupa un lugar muy especial en la valoración de Rodó hacia los intelectuales cubanos. De hecho, no hay otro intelectual cubano que goce de mayor estimación por parte del intelectual uruguayo. Según ha podido verse o intuirse por lo apuntado hasta ahora, un lugar muy particular ocupa José Martí en la visión de Rodó, incluso más allá del radio de Cuba y de los intelectuales cubanos. Como escritor y como líder político (hasta donde puede sostenerse esa diferenciación) es admirado Martí por Rodó. Martí, además, es el pensador cubano con el que suele ser comparado o más bien contrastado Rodó por los lectores de uno y otro. Al decir de San Román, por ejemplo, el propósito insatisfecho del uruguayo de escribir sobre el cubano "de alguna manera fue llevad [o] a cabo por varios críticos cubanos [como Carlos Rafael Rodríguez, Medardo Vitier, Roberto Fernández Retamar, Jorge González Rodríguez, Joaquín Santana Castillo] que trajeron a colación a Martí en sus ensayos sobre Rodó".

Como puede colegirse de mis observaciones previas, y condicionado seguramente por varias de esas lecturas contrastantes, a mí, en ese cotejo, me han llamado más la atención los puntos de contacto, las cercanías incluso epocales, entre ambos pensadores y ensayistas. Impedido ahora de extender ese cotejo al conjunto de sus respectivas obras, he optado por ceñirlo a las producciones textuales más afines entre sí de cada uno de ellos: el ensayo "Nuestra América" (1891), de José Martí, y Ariel (1900) de José Enrique Rodó. Inevitable preguntarse si esa afinidad entre ambos textos se debe al influjo de una conciencia colectiva forjada por circunstancias 
que podrían concentrarse en torno a 1898, y que además desbordaría la obra de ambos escritores, o a la lectura directa del cubano por parte de su colega uruguayo, en cuyo caso habría que preguntarse cómo, dónde, y quién o quiénes habrían hecho de intermediarios o introductores.

Se sabe, por un lado, que Rodó fue un continuo constructor de redes de intelectuales de diversos países hispanoamericanos y de España. Sabido es, por el otro, que Martí fue un escritor que colaboró en diversos periódicos hispanoamericanos, el más famoso de los cuales fue La Nación. Martí leído en La Nación de Buenos Aires; Martí leído en publicaciones hispanas de Estados Unidos, o en El Partido Liberal de México... Ninguna de esas posibilidades ha de perder de vista la opción de los puntos de contacto e incluso coincidencias a partir de los efectos de ciertas circunstancias históricas en torno a las cuales se orientaron sus respectivas obras, como también la de otros pensadores contemporáneos. Real de Azúa llega a afirmar que "buena parte de sus opiniones fuer[o]n tomadas demasiado puntualmente de otros testimonios -algunos, argentinos [...]-"(1985: xxviii), y "también que otros enfoques latinoamericanos, si bien menos accesibles y menos ceñidos - caso de los de Martí, Varona, Ugarte, Vasconcelos-, ya h[abí] an ofrecido o lo hicier[o]n a poco andar visiones más concretas, directas, ricas y matizadas que la que en Ariel se expide". ${ }^{2}$ Así que el elemento epocal, los aires de época, no pueden ser desestimados a la hora de indagar en torno al origen del contacto de Rodó con la obra de Martí.

Aun así, hurgando en la dirección de algún mediador entre ellos, es inevitable recordar que el cubano se desempeñó como representante

12 En senda similar, Bernecker (2000: 38) ha sostenido que "Rodó recogió en su obra, metafórica y literariamente, una idea que ya estaba en el aire, expresada décadas antes ya por el chileno Francisco Bilbao - una visión que contraponía una América anglosajona, pragmática y materialista a una América hispánica, esteticista y espiritualista" (2000: 38). De hecho, la idea de novedades que no lo eran tanto ya para entonces él la extiende más allá de uno u otro intelectual por separado: "Muchos de los aspectos supuestamente 'nuevos' en relación con el 98 y los acontecimientos finiseculares no eran, pues, tanto, sino que venían de más atrás: el temor al expansionismo norteamericano, las corrientes unitarias hispanoamericanas, la re-interpretación y revalorización de las 'razas' latina y anglosajona" (39). 
diplomático del gobierno uruguayo en Nueva York durante la segunda mitad de la década de 1880 e inicios de la siguiente, función en la cual llegó a establecer relaciones de notable confianza con el diplomático uruguayo Enrique Estrázulas. ${ }^{13}$ Imprescindible todavía más en la exploración del punto de contacto entre ambos escritores sería Rubén Darío, quien por ser admirado (no sin reservas) por Rodó y ser él mismo admirador de Martí, pudo servir de guía en la distancia para orientar el interés de Rodó como lector hacia Martí. La admiración dariana hacia Martí es manifiesta ya desde la segunda mitad de la década de 1880, aproximadamente una década antes de su conocimiento personal de Rodó. ${ }^{14}$ Si tan generoso fue el nicaragüense en su estimación de Martí por escrito, no hay por qué suponer que no lo haya sido igualmente en sus diversas redes de relaciones, alguna de las cuales, a su vez, alcanzaría eventualmente el oído de Rodó. Rufino Blanco Fombona, García Godoy y otros corresponsales de Rodó que conocieron personalmente al escritor cubano pudieron también ejercer como introductores del mismo ante éste, aun sin proponérselo.

Claro está que ese contacto bibliográfico o más bien hemerográfico no garantizaría que uno de los textos de Martí leídos por Rodó fuera "Nuestra América", un texto publicado en Nueva York, y luego reproducido en El Partido Liberal de México. No desestimable entonces es que el mucho cotejo y aun contraste entre ambos textos sea parte ya de las respectivas historias de efectos de cada uno: los lectores de uno y otro podrían haber sido quienes los pusieron en contacto a partir de ciertas comunidades temáticas y cronológicas percibidas entre ambos. Los propios textos inducen a aproximarlos, lo que a su vez lleva a contrastar sus respectivos programas. Esto es particularmente válido, cuando los dos ensayos son

13 En el índice onomástico de las Obras completas de Rodó (1967) no hay entrada para el apellido Estrázulas.

14 Según lo ha señalado Emir Rodríguez Monegal en la edición de las Obras completas de Rodó: "Ya en 1897 puede apuntarse el conocimiento personal, y no sólo literario, de Darío" (1967: 1364). "[S]ólo a partir de 1897 se acerca [Rodó], personal y literariamente, a Darío. // A fines del mismo año visita a Darío en Buenos Aires [... ]" (1967: 86). 
insertados en la constelación política, económica y sociocultural que en Hispanoamérica y Occidente está centrada por el redefinitorio año 1898.

Para mayores posibilidades comparativas entre uno y otro ensayo fundacional, sucede que ambos corresponden a la década de 1890 (uno al inicio y otro al final), y, como ya lo había señalado, los dos organizan sus respectivos volúmenes de sentido en torno al acontecimiento sociopolítico que estallaría en 1898, el cual se visualiza en "Nuestra América", todavía como una posibilidad inminente, a tal punto que todo el ensayo se orienta a prevenir a sus destinatarios con respecto a él para tratar de evitarlo; mientras que, ya consumado tal acontecimiento (a partir de 1898), en Ariel se intenta reducir o controlar sus peligros o daños: la absorción de Cuba por parte de Estados Unidos considerada como punto de inflexión redefinitoria de la geopolítica entre las dos grandes porciones del continente y la consiguiente expansión en grande de Estados Unidos sobre las antiguas colonias del casi o recién perimido imperio español. El acontecimiento histórico al que intenta adelantarse el más antiguo de esos ensayos funciona como detonante para el otro.

En el caso de Rodó ya es tópica la fuerte impresión de rechazo que le suscitó la noticia de la ocupación de Cuba por Estados Unidos. Si tan dispuesto quedó Rodó a alertar sobre las implicaciones de ese acontecimiento político, no es forzado entonces remontar a 1898, incluso más que a 1899, el inicio de la concepción, si es que no escritura, de ese ensayo que finalmente se publicaría completo en febrero de 1900, luego de adelantar una parte en enero de ese mismo año. ${ }^{15}$ El de Martí, incomparablemente más breve, sumario y concentrado debió de ser escrito a finales del año

15 Si, por un lado, la publicación de Ariel fue anunciada para finales de 1899, por el otro, no escasean en su cuerpo mismo indicios de su arraigo temporal en las coordenadas del siglo XIX: "nuestro siglo", "estos cien años", el "siglo presente". Más precisa aún es esa ubicación en el pasaje en que contrasta "este ocaso de siglo" y "el siglo venidero"; o incluso cuando alude a "las violencias recientes de su historia" a propósito del expansionismo estadounidense. Otro indicio temporal nada equívoco viene dado por el deíctico "Y no hace aún cinco años [...]", con el que se dispone a introducir ideas de un libro publicado en 1895. 
1890, si su publicación se concretó en un órgano de prensa el primer día del año 1891.

Ante la amenaza que para la identidad no sólo cultural de la región supusieron los eventos históricos del año 1898, se entiende la prioridad concedida a ésta por ambos pensadores, dispuestos uno de ellos a defenderla preventivamente, y el otro a conservarla en medio de circunstancias muy adversas. A la previsión del cubano establecido en Nueva York correspondería la resistencia del uruguayo establecido en Montevideo.

Problemática de suyo la identidad de la región (ya desde su nombre: ¿América?, ¿Hispanoamérica?, ¿Latinoamérica? ilberoamérica?), esa condición se agrava en las circunstancias que desembocarían en 1898. Prueba de esa problematicidad en la identidad defendida por ambos ensayistas es que mientras que la identidad que se deriva de "Nuestra América" es de carácter inclusivo, la del Ariel tiende a excluir o a silenciar ciertos componentes distintivos del perfil sociocultural de la región. ${ }^{16}$ Marginados en los proyectos republicamos surgidos de las independencias políticas, indios, negros y campesinos son incluidos en la idea de identidad con que opera "Nuestra América". Por el contrario, en Ariel la identidad supranacional de la región sólo se reconoce en su ascendencia latina o euro-latina, acaso por considerar a esta como la definitoria en el perfil todavía no sellado de la región, o tal vez como la única en condiciones de oponer resistencia a la amenaza de desfiguración que implicaría la inminente convivencia con la cultura proveniente de Estados Unidos. En cualquier caso, parece inevitable coincidir con Brotherston cuando afirmaba que "A pesar de las primeras apariencias, su obra elimina sutilmente la necesidad de considerar o de tomar en cuenta la veta americana que enriqueció a Martí [... ]" (2000: 70).

En el capítulo de su ensayo que él dedica a impugnar el carácter modélico de la cultura estadounidense para la América Latina, se ofrece un razonamiento que ayuda a entender la apuesta de Rodó por el componente latino en el perfil identitario de la región: "Falta, tal vez, en nuestro carácter colectivo, el contorno seguro de la 'personalidad'. Pero en ausen-

16 En lo sucesivo aprovecho algunas ideas de mi estudio "Dos ensayos, una América: la 'nuestra' de Martí, la 'nuestra' de Rodó” (Sánchez 2016). 
cia de esa índole perfectamente diferenciada y autonómica, tenemos - los americanos latinos - una herencia de raza, una gran tradición étnica que mantener, un vínculo sagrado que nos une a inmortales páginas de la historia, confiando a nuestro honor su continuación en lo futuro". De Europa occidental proviene ese otro modelo civilizatorio para la "personalidad" aún en ciernes de la América Latina.

Porque sería tal vez lo más cercano a "personalidad" y lo que dispone de una reconocida herencia cultural; a ese componente él se aferra como el único capaz de oponer resistencia a la "conquista moral" que "la poderosa federación va realizando entre nosotros". La cultura letrada que tanto cuenta en la visión del joven ensayista para su defensa de la identidad de "nuestra América latina" él la reconoce en la herencia latina, no en la indígena, ni en la de ascendencia africana.

Contrario con respecto a ese diagnóstico, en el caso de "Nuestra América" la base o el origen de tal problema identitario se hace descansar precisamente sobre la actuación histórica que hasta ese momento ha mostrado la población de ascendencia latina. En correspondencia con ese desplazamiento del acento, la identidad se visualiza como algo a recuperar y refrendar, ya no de colonizadores consumados o de potenciales conquistadores extranjeros, sino de los sectores de élite criollos, en unas circunstancias en que la proximidad del centenario (el primero) de la independencia política respecto de España, favorece la ilusión de que ella está definida y asegurada, no obstante "la importación excesiva de las ideas y fórmulas ajenas" por un lado, y la emergencia de una nueva potencia interesada en cubrir la recién desocupada función imperial ("da por bueno el orden universal, sin saber de los gigantes que llevan siete leguas en las botas, y le pueden poner la bota encima") por el otro (Martí 2000: 21, 9).

En el Ariel, la identidad, de raigambre latina, se trata como algo a conservar y reforzar en circunstancias adversas para ello, debido a la expansión del modelo cultural estadounidense estimulado por su reciente victoria militar sobre el imperio español en el Caribe. De ahí el sobresalto que embarga a Próspero-Rodó ante "la visión de una América deslatinizada 
por propia voluntad, sin la extorsión de la conquista, y regenerada luego a imagen y semejanza del arquetipo del Norte" (Rodó 2014: 131).

Previsible parcialmente, a esta luz, es la convergencia de ambos ensayos en torno al reconocimiento de la imitación de modelos foráneos como un problema de desvío o interferencia en relación con la identidad regional, y su consiguiente crítica: "se imita demasiado, y la salvación está en crear", escribe Martí de manera casi aforística (2000: 24). Y Rodó, tras razonar que "en sociabilidad, como en literatura, como en arte, la imitación inconsulta no hará nunca sino deformar las líneas del modelo", sentencia que "el cuidado de la independencia interior - la de la personalidad, la del criterio- es una principalísima forma de respeto propio", con una validez todavía mayor en las naciones que en los individuos (2014: 132-133).

Otra diferencia a considerar en ese aspecto, sin embargo, es que mientras Rodó ciñe el radio de su advertencia a la relación de América Latina con Estados Unidos, a partir de la excesiva admiración por su cultura entre las muchedumbres y los sectores dirigentes ("nordomanía") que él percibe en las sociedades que conforman esa región, la de Martí abarca tanto a Estados Unidos como a Europa Occidental (Francia incluida). Al término "nordomanía" de Rodó corresponderá "yanquimanía" en Martí en un artículo de 1894 publicado en el periódico Patria.

Si frente a la amenaza estadounidense Rodó busca alinear a la región con las naciones europeas (y en particular, Francia) que podrían representar un contrapeso a la pérdida de "latinidad" en que él cifra el nervio básico del perfil identitario de la región, Martí advierte un peligro en cualesquiera de esas naciones a cuya historia puedan acudir los sectores dirigentes de Hispanoamérica para explicar la propia de la región que él designa "nuestra América mestiza", o fundar el modelo adecuado de organización sociopolítica.

Comprensible al respecto es que aun siendo un admirador de la herencia greco-latina clásica, Martí no tenga reparos en proclamar su preferencia por las culturas aborígenes americanas: "Nuestra Grecia es preferible a la Grecia que no es nuestra". "Preferible", aclara él, porque "nos es más 
necesaria". Si de conocernos o reconocernos se trata, es impostergable entonces, no la omisión practicada por Rodó, sino esa recuperación de la raíz propia escamoteada o subvalorada, así en la Colonia como en la república, precisamente en virtud de la dialéctica, muy colonial, de menosprecio propio/imitación foránea que ha regido la actuación de los sectores dirigentes de Hispanoamérica en sus vínculos políticos, económicos y culturales con las (ex-)metrópolis. Aunque, eso sí, nada de aislacionismo proteccionista: "Injértese en nuestras repúblicas el mundo; pero el tronco ha de ser el de nuestras repúblicas". La metáfora del cultivo (injerto: jardinería, agricultura) escenifica a pequeña escala las ideas de novedad y de apego a lo propio que tanto van a singularizar la noción de cultura con que se opera en este diagnóstico.

Seguidor también de la herencia greco-latina clásica, Rodó, en cambio, ve en la Grecia histórica el origen, el modelo o un referente básico de todo lo que para él cuenta como cultura, que es, asimismo, todo cuanto puede asociarse de manera legítima y favorable con su emblemático personaje Ariel. En abono de su honestidad, hay que añadir que ese reconocimiento del carácter modélico a la civilización griega clásica no le impedirá criticarla, aunque sea de manera velada, por haber delegado el trabajo a "la abyección de la esclavitud", pues "la esclavitud afea al mismo tiempo que envilece".

Un dato más a considerar sobre identidad, tanto de la región pensada como sobre el vehículo de esa interpretación, es la gravitación de la poesía: mientras que la poesía parece ausente o, lo que tal vez sea peor, fuera de lugar, en un ensayo, como el de José Martí, en el que se le hace figurar siempre como rezagada (sea por "la melena zorrillesca" que debe cortarse, sea por "la oda" que no debe ser premiada) con respecto a la orientación del arte en los nuevos tiempos o a las necesidades más apremiantes de la región correspondiente; en el otro, el de Rodó, ella llega a sentirse como recargada, por su continua presentación, ya directa, ya alusiva, en nombres de autores, de corrientes artísticas e incluso en versos que respaldarían la belleza del texto mismo que los acoge.

Sin embargo, una revisión más detenida de sus huellas o marcas en esos textos pronto lleva a sospechar que la poesía no es un dato más, 
cuestionado o de mero ornato, en sus respectivas propuestas. El hecho mismo de que se le tenga en cuenta en ensayos con tan fuerte resonancia política a propósito de una región cuya identidad cultural o independencia política ambos sienten en peligro o amenazada es un primer indicio para abonar la reconsideración del lugar o la función de la poesía en los diagnósticos que aporta cada uno. Y luego, que se le invoque y cuente con ella desde un trasfondo socioeconómico en que se le cuestiona su razón de ser, supone una confianza grande en ella.

Evidente es que en "Nuestra América", su estilo resulta más poético: por su intensa y novedosa tropología, por su enunciación como de rapto, por las inscripciones versales que traslucen varios de sus párrafos, aun cuando no falte alguna reserva hacia ciertas realizaciones históricas y ciertos realizadores de ella. La reserva que se manifiesta hacia la poesía en ese ensayo acaso sea la manera mejor de defenderla, cuando su valencia etimológica se hace valer más allá del radio habitual de su presencia. Poesía, conviene recordarlo, remite a creación, etimológicamente, rasgo que, entendido también como creatividad, es sobresaliente en este ensayo, tanto en la posición que él adopta frente al que llama "enigma hispano-americano", como en el lenguaje al que acude para exponerlo/descifrarlo. Y es que la creación de un lenguaje acorde con la singularidad de tal "enigma" es condición y parte de la solución de éste. Creativo sobremanera, por ejemplo, es que el término mismo de creación pueda referirse ahí no a la poesía, a la literatura o al arte, sino al campesino, al campo o al buen gobernante, con lo que desborda ampliamente el radio de empleo suyo concebible o hasta aceptable para Rodó.

La densidad tropológica de su lenguaje propicia la inclusión de imaginarios colectivos correspondientes a los mismos sectores sociales marginados que el ensayista ha propuesto rescatar en su visión de la "América nueva": "del Bravo a Magallanes, sentado en el lomo del cóndor, regó el Gran Semí, por las naciones románticas del continente y por las islas dolorosas del mar, la semilla de la América nueva" (Martí 2000: 30). El sembrador de esa semilla, "el gran Semí", corresponde a imaginarios de "Nuestra Grecia", y, distintivo de su fauna es el medio que usa para transportarse y abarcar a toda la "América nueva". 
Cerrado también con la imagen de un sembrador el Ariel que había iniciado con la imagen de la semilla ("la simiente de una palabra oportuna" [I, 24]) y de una "inmortal vegetación", en su caso el beneficiario de esa siembra es la muchedumbre que los discípulos de Próspero habrán de ganar para la causa del "sentimiento de lo hermoso": "Sobre su masa indiferente y oscura, como tierra del surco, algo desciende de lo alto. La vibración de las estrellas se parece al movimiento de unas manos de sembrador" (2000: 99). Mientras aquí la siembra es obra de la naturaleza concebida a la manera panteísta, en "Nuestra América" lo es de un recuperado representante de las culturas protoamericanas.

Curiosamente, "Nuestra América" no ha tenido la ascendencia sobre la tradición poética que tan notable me ha resultado en esta nueva visita a Ariel. Nutrido por la poesía de otros, el ensayo de Rodó ha vuelto a nutrir la poesía de otros. Nutrido por la poesía de sí y por la de algunas culturas originarias del continente, el ensayo "Nuestra América" se ha mostrado más autónomo, acaso por más autóctono.

\section{BIBLIOGRAFÍA}

Bernecker, Walther Ludwing. "El fin de siglo en el Río de la Plata: Intereses internacionales y reacciones latinoamericanas". Ottmar Ette y Titus Heydenreich (eds.). José Enrique Rodó y su tiempo (Cien años de Ariel). Frankfurt am Main/Madrid: Vervuert/Iberoamericana, 2000. 15-39.

Bourdieu, Pierre. "La cultura está en peligro". Trad. Desiderio Navarro. Criterios 33 (2002): 365-374.

BROTHERSTON, GORDON. "La América de José Enrique Rodó, sus banderas y sus silencios". Ottmar Ette y Titus Heydenreich (eds.). José Enrique Rodó y su tiempo (Cien años de Ariel). Frankfurt am Main/Madrid: Vervuert/Iberoamericana, 2000. 59-71.

Castro Morales, BelÉn. "La correspondencia inédita entre José Enrique Rodó y Rafael M. Merchán (Algo más sobre Cuba en la génesis de 
Ariel)". Lo que los papeles cuentan/2. Montevideo: Biblioteca Nacional de Uruguay, 2013. 177-199.

José Enrique Rodó (Estudio crítico). Madrid: Fundación Ignacio Larramendi, 2016.

Cesana, RAFFaEle. "El diálogo entre la misiva y el ensayo: la correspondencia entre los hermanos Henríquez Ureña y José Enrique Rodó”. Liliana Weinberg (coord.). El ensayo en diálogo. Vol. 2. México: UnAM, 2017. 215-247.

DARío, RubÉn. "José Martî". Iris M. Zavala selección, prólogo y notas. Rubén Darío. El Modernismo y otros ensayos. Madrid: Alianza Editorial, 1989. 105-115.

"La insurrección en Cuba". La República de Panamá y otras crónicas desconocidas. Jorge Eduardo Arellano selección, estudio y notas. Managua: Academia Nicaragüense de la Lengua, 2011. 189-198. Diccionario de la literatura cubana. Instituto de Literatura y Lingüística de la Academia de Ciencias de Cuba. 2 vols. La Habana: Editorial Letras Cubanas, 1980.

García Morales, Alfonso. "Un capítulo del 'arielismo': Rodó en México". Leonor Fleming y Ma. Teresa Bosque Lastra (coords.). La crítica literaria española frente a la literatura latinoamericana. México: CCyDEL-UnAm 1993 (Col. Panoramas de Nuestra América, 2). 95-105.

HenríqueZ Ureña, Pedro. Memorias. Diario. Notas de viaje. Enrique Zuleta Álvarez introducción y notas. México: FCE, 2000. 2a. ed. corregida y aumentada.

MARTí, José. Nuestra América. Edición crítica. Cintio Vitier investigación, presentación y notas. La Habana: Centro de Estudios Martianos, 2000.

PlesCH Svend. "Ariel y la ilusión del hombre nuevo. Apuntes sobre la temprana recepción de Rodó en Cuba". José Enrique Rodó y su tiempo. (Cien años de Ariel). Frankfurt am Main/Madrid: Vervuert/ Iberoamericana, 2000. 119-135.

Real de azúa, Carlos. "Prólogo a Ariel". José Enrique Rodó. Ariel. Motivos de Proteo. Carlos Real de Azúa prólogo, Ángel Rama edición y cronología. Caracas: Biblioteca Ayacucho, 1985. ix-xxxiii. 2a ed. 
Rodó, JosÉ EnRiQue. Obras completas. Emir Rodríguez Monegal introducción, prólogo y notas. Madrid: Aguilar, 1967. 2ª ed.

. "Ariel". Cinco ensayos (Montalvo, Ariel, Bolivar, Rubén Dario, Liberalismo y jacobinismo). Hugo D. Barbagelata prólogo. México: ConaCulta, 2014. (Col. Cien de Iberoamérica). 89-161.

RodríGuez Monegal, Emir. "Introducción general". José Enrique Rodó. Obras completas, Madrid: Aguilar, 1967. 19-139.

SÁnchez Aguilera, Osmar. "Dos ensayos, una América: la 'nuestra' de Martí, la 'nuestra' de Rodó". Las martianas escrituras. La Habana: Centro de Estudios Martianos-Instituto Cubano del Libro, 2016. 249274. $2^{a}$ edición revisada y aumentada.

SAn Román, Gustavo. "La recepción de Rodó en Cuba". Revista de la Biblioteca Nacional 3.1.3 (2009): 71-86. En línea en: http://www. cervantesvirtual.com/obra-visor/la-recepcion-de-rodo-en-cuba/htm1/7b64bbfc-a0f7-11e1-b1fb-00163ebf5e63_3.html (Consultado el 2 de junio de 2017).

VARGAS LLOSA, MARIO. La civilización del espectáculo. Madrid: Alfaguara, 2012.

Zaldumbide, GonZalo. José Enrique Rodó. Madrid: Editorial América, 1919. 